\title{
Neglected tropical diseases in Brazilian children and adolescents: data analysis from 2009 to 2013
}

\author{
Eduardo Brandão ${ }^{1,2^{*}}$, Sebastián Romero ${ }^{2}$, Maria Almerice Lopes da Silva ${ }^{3}$ and Fred Luciano Neves Santos ${ }^{4}$
}

\begin{abstract}
Background: Neglected tropical diseases (NTDs) prevail in conditions of poverty and contribute to the maintenance of social inequality. Out of the NTDs prioritized by the Brazilian Ministry of Health, four parasitic infections require mandatory notification: acute Chagas disease, leishmaniasis, malaria, and schistosomiasis. Data on the behaviour of these NTDs in the young population are currently limited. This study seeks to analyse the epidemiological aspects of these parasitic infections in children and adolescents in Brazil.

Methods: A retrospective exploratory ecological study was conducted. A spatial analysis of the cases reported between 2009 and 2013 in individuals aged between 0 and 19 years that were notified through the Health Notification Aggravation Information System (SINAN) was performed.

Results: In total, 64,567 cases of cutaneous and visceral leishmaniasis, malaria, schistosomiasis, and acute Chagas disease were recorded in the SINAN database, representing a rate of 20.15 cases per 100,000 inhabitants. The average age of the cases was 12.2 years and $62.32 \%$ were male. Four hundred and three deaths related to these obligatorily reported parasites were recorded, indicating a case fatality rate of $0.62 \%$. Visceral leishmaniasis and acute Chagas disease had the highest rates of lethality. A heterogeneous spatial distribution of the studied parasites was observed.

Conclusions: The number of cases and the lethality rate described in this study show that these diseases still represent a serious problem for public health in Brazil. This points to the need to encourage new research and the reformulation of social, economic, and public health policies aimed at ensuring better health and living conditions for all individuals, especially those among the populations considered vulnerable, as is the case of the young.
\end{abstract}

Keywords: Parasites, Visceral leishmaniasis, Malaria, Schistosomiasis, Chagas disease, Disease notification, Residence characteristics, Brazil

\section{Multilingual abstracts}

Please see Additional file 1 for translations of the abstract into the five official working languages of the United Nations.

\section{Background}

Neglected tropical diseases (NTDs) comprise a large group of tropical infections that are strongly associated with poverty and concentrated mainly in slum and

\footnotetext{
* Correspondence: brandaoe@cpqam.fiocruz.br

${ }^{1}$ National Reference Service for Filariasis, Aggeu Magalhães Institute

(Fiocruz-PE), Recife, Pernambuco, Brazil

${ }^{2}$ Faculty of Medical Sciences, National University of Rosario, Rosario, Santa Fe, Argentina

Full list of author information is available at the end of the article
}

remote rural areas of developing regions in Africa, Asia, and the Americas [1]. These diseases are characterized by their high prevalence, chronicity, and disabling features [2]. The World Health Organization (WHO) recognizes 17 NTDs that blight the lives of a billion people in 149 countries and threaten the health of millions more [1].

In Brazil, nine NTDs affect the population, of which seven (dengue, acute Chagas disease, leishmaniasis, malaria, schistosomiasis, leprosy, and tuberculosis) entail obligatory notification and are considered priorities for prevention and control, owing to their severity and harmful socioeconomic consequences (Additional file 2) [3-5]. 
From a biological perspective, children and teenagers represent a group that is vulnerable to NTDs owing to malnutrition and impairment of cognitive development, which demands more attention from healthcare agencies $[6,7]$.

Leishmaniasis, in its various forms, has been reported in urban areas of Brazil [8-11]. It completely destroys the mucous membranes of the mouth and throat and leaves permanent scars, leading to massive suffering. Visceral leishmaniasis (VL) occurs in 12 countries in Latin America, with more than 95\% of cases reported in Brazil [12]. This disease attacks internal organs and is fatal if neglected. The age of the infected individual influences the outcome of infection, as a high proportion of patients are children [13]. A study carried out in a pediatric referral hospital in Pernambuco showed a high mortality rate resulting from VL in children aged below 13 years [14].

Malaria, another disease of public health importance, is equally fatal if untreated. Pregnant women and children below the age of 5 years are the most vulnerable groups $[15,16]$.

Schistosoma mansoni infection is also of considerable public health importance in tropical countries, mainly affecting school-age children, women of childbearing age, and workers who are in frequent contact with contaminated fresh water [17]. The damage to the intestinal tissue results from the large numbers of eggs released by the flukes. If untreated, the disease can lead to longterm, irreversible health effects, including periportal fibrosis, liver cirrhosis, and obstruction resulting from the depositing of eggs in the small portal venules [18]. Children are especially vulnerable in endemic areas, where poor hygiene, lack of sanitation, and recreational water use prevail [19]. Severe schistosomiasis impairs cognitive development, disrupts school attendance, contributes to malnutrition in children, and causes poor growth, although the effects are usually reversible with treatment [20].

Chagas disease is a vector-borne disease responsible for 5.7-9.4 million cases in the continental Western Hemisphere [21, 22]. Every year, due to the disease, 14,000 deaths occur in 22 endemic countries in Latin America [23]. The epidemiological pattern of Chagas disease has changed because of the interruption of transmission following Triatoma infestans elimination in Brazil and other areas of Latin America [24]. Protracted infection can lead young adults to develop heart conditions that require hospitalization, thereby reducing the labour force [20].

Knowledge of the distribution of NTDs in endemic areas is fundamental to the follow-up and assessment of interventions and the effectiveness of control measures. Attention has recently turned to epidemiological studies considering the spatial distribution of NTDs in the general population [25-28]. Owing to the scarcity of information describing NTDs in Brazilian children and adolescents, the epidemiological aspects and distribution of visceral and cutaneous leishmaniasis, acute Chagas disease, malaria, and schistosomiasis in individuals aged up to 19 years reported in the Health Notification Aggravation Information System (SINAN) database from 2009 to 2013 were assessed.

\section{Methods \\ Study area}

This study was conducted in Brazil, the largest country in Latin America and the fifth largest in the world, with a total area of $8,515,767 \mathrm{~km}^{2}$. The Brazilian Federation comprises 26 states and a federal district (containing the capital Brasília), which may be grouped into five regions: North, Northeast, Central West, Southeast, and South (see Fig. 1). According to the 2010 demographic census, the total population of Brazil was 190,755,799 inhabitants, $32.99 \%$ of whom were children or adolescents aged up to 19 years (available at http://www.ibge.gov.br).

\section{Study design}

An ecological retrospective study was conducted using data obtained from the open-access SINAN database, taking into account reported cases of cutaneous and visceral leishmaniasis, malaria, schistosomiasis, and acute Chagas disease in each notification microregion from 2009 to 2013 (available at http://datasus.saude.gov.br). All reported cases aged between 0 and 19 years were included in this study.

The SINAN database provides information for the creation of indicators for monitoring the distribution of certain diseases in Brazil and thereby supports the development of prevention, interception, and control measures. Cases reported after 2013 were excluded due to possible delays in notification. Datasets by microregion, year, age group, gender, and clinical evolution were obtained and analysed. Additionally, datasets of clinical disorder and co-infection with HIV were produced for cutaneous and visceral leishmaniasis, respectively. Population data were acquired from the Brazilian Institute of Geography and Statistics (IBGE), and were supported by national census data from 2010 and official estimates for the other years (available at http://www.ibge.gov.br).

\section{Statistical analysis and geoprocessing}

Statistical analyses were performed using the Epi Info ${ }^{\mathrm{Tm}}$ software (version 6.04d, Centre for Disease Control and Prevention, www.cdc.gov/epiinfo). Categorical variables were analyzed using the chi-square test. Relative risk and $95 \%$ confidence intervals (CIs) were used to evaluate significant effects of each variable; if the $95 \% \mathrm{CIs}$ did not 


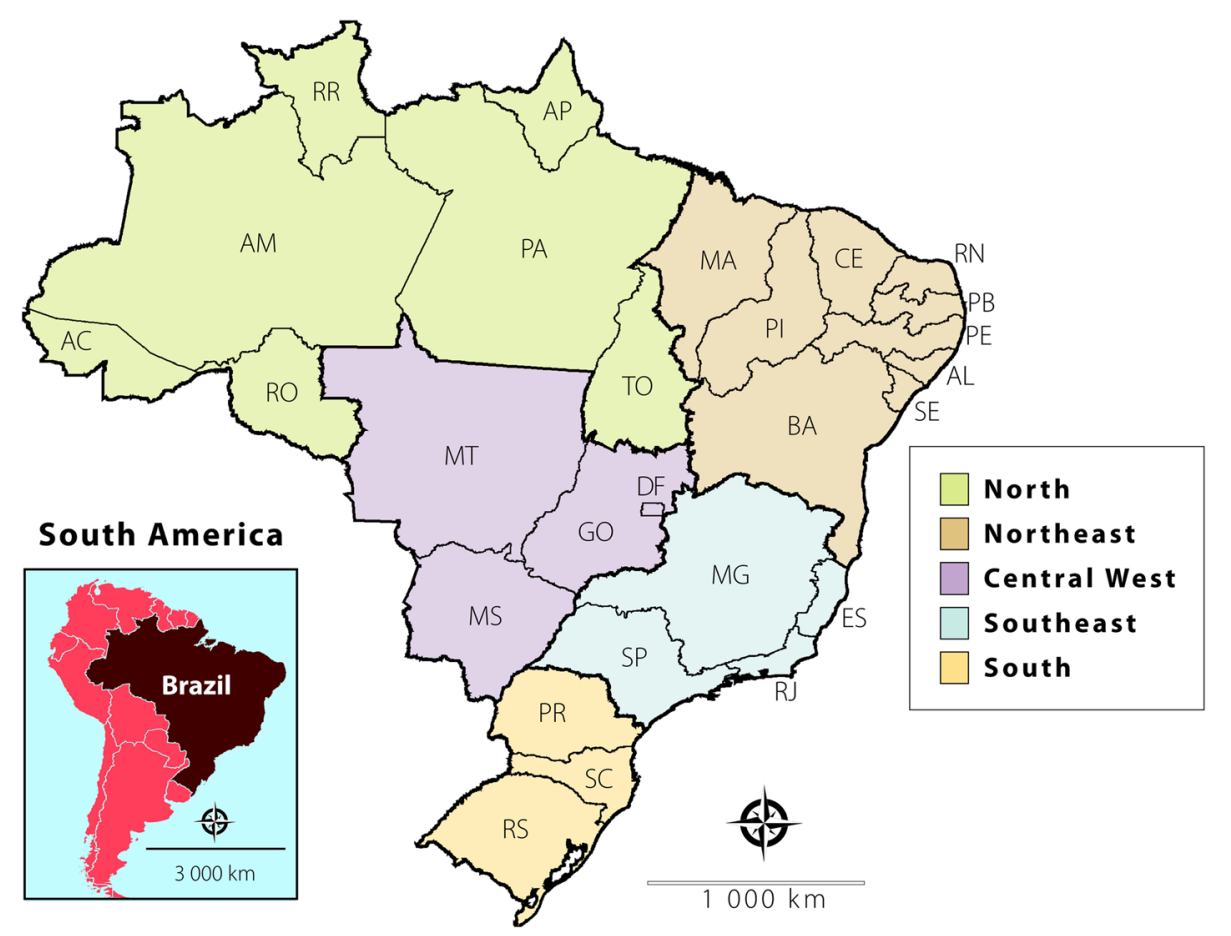

Fig. 1 Political and administrative division of Brazil into five regions. North (AC: Acre, AM: Amazonas, AP: Amapá, RO: Rondônia, and RR: Roraima); Northeast (AL: Alagoas, BA: Bahia, CE: Ceará, MA: Maranhão, PB: Paraíba, PE: Pernambuco, PI: Piauí, RN: Rio Grande do Norte, and SE: Sergipe); Central West (DF: Distrito Federal, GO: Goiás, MS: Mato Grosso do Sul, and MT: Mato Grosso); Southeast (ES: Espírito Santo, MG: Minas Gerais, RJ: Rio de Janeiro, and SP: São Paulo); and South (PR: Paraná, RS: Rio Grande do Sul, and SC: Santa Catarina)

contain unity, the effect was considered significant. A $P$-value of less than 0.05 was considered significant for all tests. Geographic information system techniques and spatial analysis tools were employed to determine the geographical distribution of cutaneous and visceral leishmaniasis, malaria, schistosomiasis, and acute Chagas disease in Brazil. The microregion was adopted as a unit of analysis in order to obtain improved accuracy concerning the differences among regions. Thematic maps were drawn in accordance with the rate per 100,000 inhabitants. Digital maps were obtained from the IBGE cartographic database in shape file (.shp), which were formatted and analysed using TerraView version 4.2, a public-access software provided by the National Institute for Space Research (www.dpi.inpe.br/terraview).

\section{Ethical considerations}

This investigation was performed according to public domain data without the possibility of identifying subjects, thereby dispensing the need for approval by an institutional review board for human research.

\section{Results}

In total, 64,567 cases of cutaneous and visceral leishmaniasis, malaria, schistosomiasis, and acute Chagas disease were recorded in the SINAN database, representing a rate of 20.15 cases per 100,000 inhabitants. The average age of the cases was 12.2 years (range $0-19$ years old), There were more cases among males than females (40,239, $62.32 \%$ were male cases). Information about gender was missing for eight reported cases (two for schistosomiasis and six for cutaneous leishmaniasis [CL]).

The average age of cases was 12.2 years (range: $0-19$ years). About a third $(21,265,32.93 \%)$ were aged 15-19 years, $18,456(28.58 \%)$ were aged $10-14$ years, and 13,299 (20.60\%) were under 4 years of age. A lower predominance was documented in individuals aged $5-9$ years $(11,547 ; 17.88 \%)$. Overall, $0.62 \%$ of the reported cases were fatal.

Cutaneous leishmaniasis was responsible for 31,178 of all reported cases $(48.29 \%)$, with a rate of 9.73 cases per 100,000 inhabitants. This infection was substantially associated with male children and adolescents aged 15-19 years (see Fig. 2a). New reported cases were consistent throughout the period of the study, except for a slight decline in 2013 (see Fig. 2b). Of these 31,178 cases, 97\% developed cutaneous disorders and 3\% presented mucosal lesions. Cases of CL were homogeneously distributed in all regions of Brazil. The areas showing the highest rates are those located in the North and Central West, with up to 870 cases per 100,000 inhabitants. However, the microregion with the highest number of reported cases was located in 


\section{Cutaneous leishmaniasis}
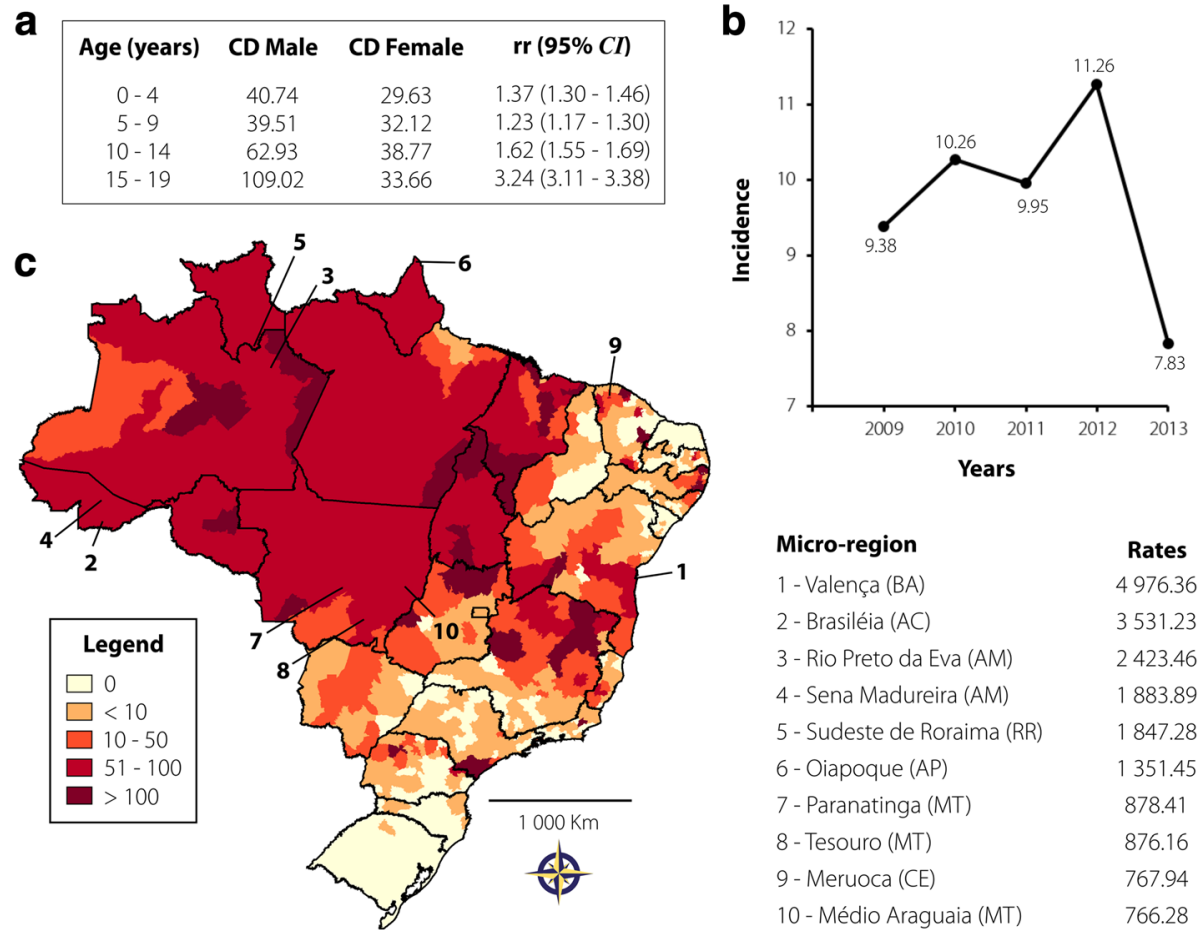

Fig. 2 Cutaneous leishmaniasis transmission in Brazil from 2009 to 2013 in individuals aged 0-19 years. a Coefficient of detection (CD) and relative risk (rr), according to age and gender; b Rate of reported cases per 100,000 inhabitants according to year of notification; c Spatial distribution adopting the microregion as the unit of analysis. On the right are the 10 microregions that reported the highest case rates per 100,000 inhabitants

the Northeast: Valença, reaching a peak of 4976.36 cases per 100,000 inhabitants. High numbers of cases were also reported in other microregions of the Northeast, such as Meruoca and Médio Araguaia. Few microregions reported new cases: Rio Grande do Norte, Rio Grande do Sul, and Santa Catarina (see Fig. 2c). The mortality rate of CL was $0.01 \%$.

Schistosomiasis presented the second most reported parasitic infection: 22,348 cases were reported (34.61\%), representing a rate of 6.98 cases per 100,000 inhabitants. The highest predominance was recorded in individuals aged 10-14 (38.53\%) and 15-19 (35.43\%) years. The proportion of cases in all age groups was found to be significantly higher in males than in females (see Fig. 3a). A pronounced decrease in the notification of new cases has been recorded from 2010 to 2013 (see Fig. 3b). From the map in Fig. 3c, it can be observed that the highest incidences of schistosomiasis were recorded in the Northeast and Southeast regions of the country. They were mainly recorded in the Southeast, precisely the northeast of Minas Gerais and east of Espírito Santo states, following the route of the main river basins. Nine of the ten microregions with the highest incidences are located in these states. Only Umbuzeiro, with 684.13 cases per 100,000 inhabitants, is located in Paraíba state, in the Northeast region. Of the total cases of schistosomiasis, $0.05 \%$ led to death.

A total of 10,379 individuals $(16.07 \%)$ with VL were identified, with a rate of 3.24 cases per 100,000 inhabitants. Of these, $6686(64.42 \%)$ were children aged up to 4 years, 1829 (17.62\%) were aged 5-9 years, 932 (8.98\%) were aged $10-14$ years, and $932(8.98 \%)$ were aged 15-19 years. Regarding gender, the infection was significantly associated with males aged 15-19 (see Fig. 4a). Co-infection with HIV was reported in $7.14 \%$ of these individuals. The number of new cases during the period analysed was almost constant, with a slight reduction from 2012 to 2013 (see Fig. 4b). Figure 4c shows the areas with the highest incidence. Araguaína, Bico do Papagaio, Porto Nacional, Sobral, Cametá, Conceição do Araguaia, Tomé-Açú, and Teresina microregions presented more than 100 cases per 100,000 inhabitants. Other areas from Bahia (Irecê) and Mato Grosso do Sul (Campo Grande) were also affected, reporting 139.85 and 190.29 cases per 100,000 inhabitants, respectively. Of all the NTDs studied, VL had the highest death rate (3.72\%).

Malaria was reported in 429 cases $(0.66 \%)$, with a rate of 0.13 cases per 100,000 inhabitants. High incidence was observed in individuals aged $15-19$ years (41.49\%), followed by $10-14$ years $(19.35 \%), 4$ years $(16.08 \%), 5-9$ years 


\section{Schistosomiasis}
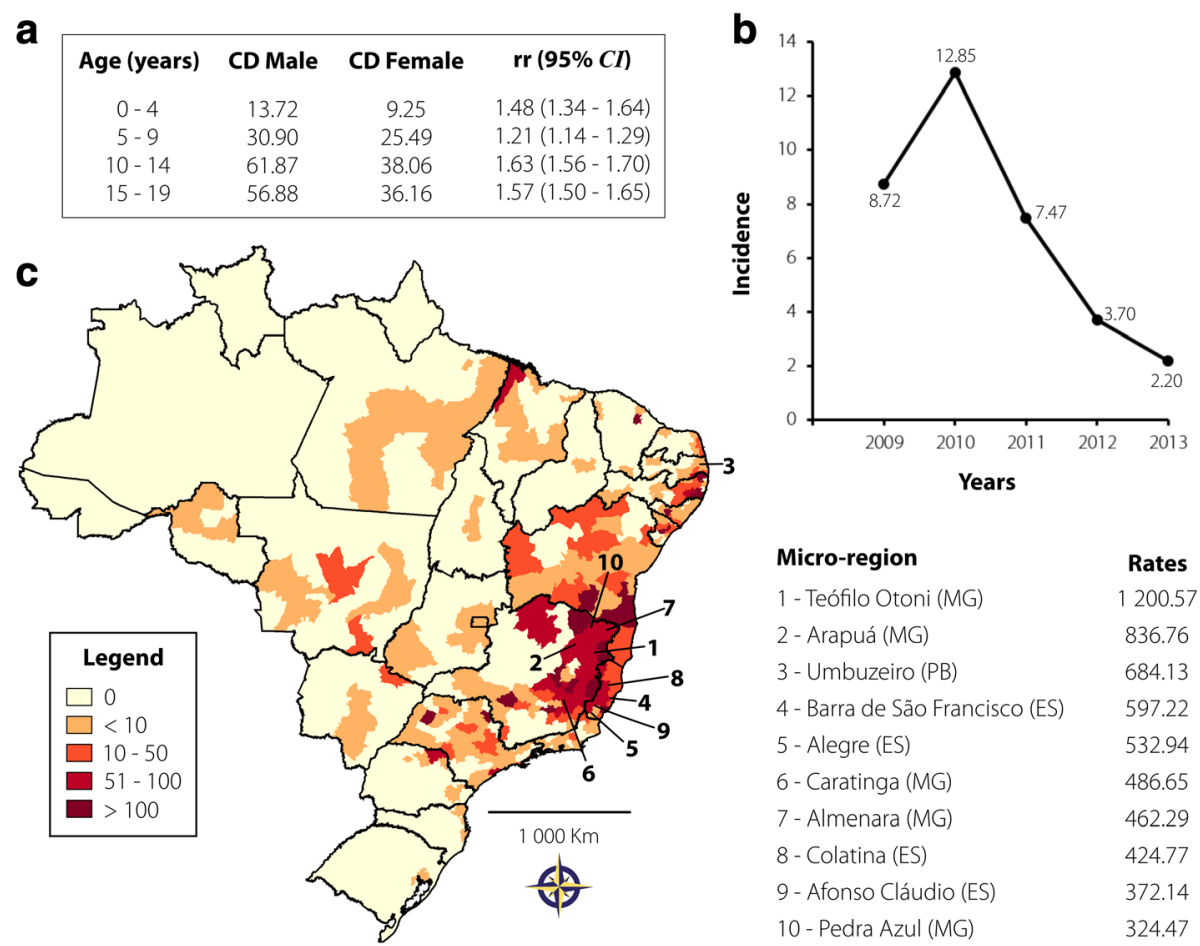

Fig. 3 Schistosomiasis transmission in Brazil from 2009 to 2013 in individuals aged 0-19 years. a CD and rr, according to age and gender; $\mathbf{b}$ Rate of reported cases per 100,000 inhabitants according to year of notification; c Spatial distribution adopting the microregion as the unit of analysis. On the right are 10 microregions that reported the highest case rates per 100,000 inhabitants

(15.15\%), and up to 1 year (7.93\%). The occurrence of the infection was higher in males only in the $0-4$ and 15-19-year age groups (see Fig. 5a). As according to Fig. 5b, the number of reported cases have reduced from 2011 to 2013. The spatial distribution of malaria cases throughout the period analysed was heterogeneous, with a high concentration in Barra de São Francisco, Foz do Iguaçu, Bom Jesus da Lapa, Baixo Parnaíba Piauiense, and Santa Teresa microregions, which presented rates higher than 15 cases per 100,000 inhabitants (see Fig. 5c). No data about mortality from malaria were available.

Acute Chagas disease presented the lowest number of reported cases: 233 reported cases $(0.36 \%)$, representing a rate of 0.07 cases per 100,000 inhabitants. There were no gender differences with regards to age groups (see Fig. 6a) and a slight reduction in the number of new cases was observed from 2011 to 2013 (see Fig. 6b). The spatial distribution rates are depicted in Fig. 6c. Overall, a concentration of new cases in the North region is evident, more precisely in Pará, Amazonas, and Amapá states. Furo de Breves and Cametá, in Pará, showed a rate of higher than 25 cases per 100,000 inhabitants. Some areas of other Brazilian regions were also affected, varying from 3.43 to 4.24 cases per 100,000 inhabitants (Alto Mearim e
Grajaú, Chapada do Apodi, Guarapari). Acute Chagas disease had the second highest mortality rate (1.72\%).

\section{Discussion}

The distribution of four NTDs in Brazil over a five-year period has been described in this study. In general, NTDs, such as malaria, acute Chagas disease, leishmaniasis (visceral and cutaneous), or schistosomiasis, impair lives in Brazil, affecting more than 20 per 100,000 inhabitants aged up to 19 years.

The highest number of reported cases is attributed to CL, followed by schistosomiasis, VL, malaria, and acute Chagas disease. Owing to the extensive geographic distribution of these diseases, particularly remarkable for $\mathrm{CL}$, control efforts and elimination actions constitute a large-scale strategy. The adoption of the epidemiologic triad model as a preventive measure can interrupt the interaction among its constituent factors (host-antigenenvironment) reducing the reporting of new cases. In line with this strategy, the Southern Cone Initiative successfully halted the transmission of Chagas disease by eliminating domestic populations of $T$. infestans and interrupting transfusional Chagas disease in vast areas of previously endemic regions [24]. 


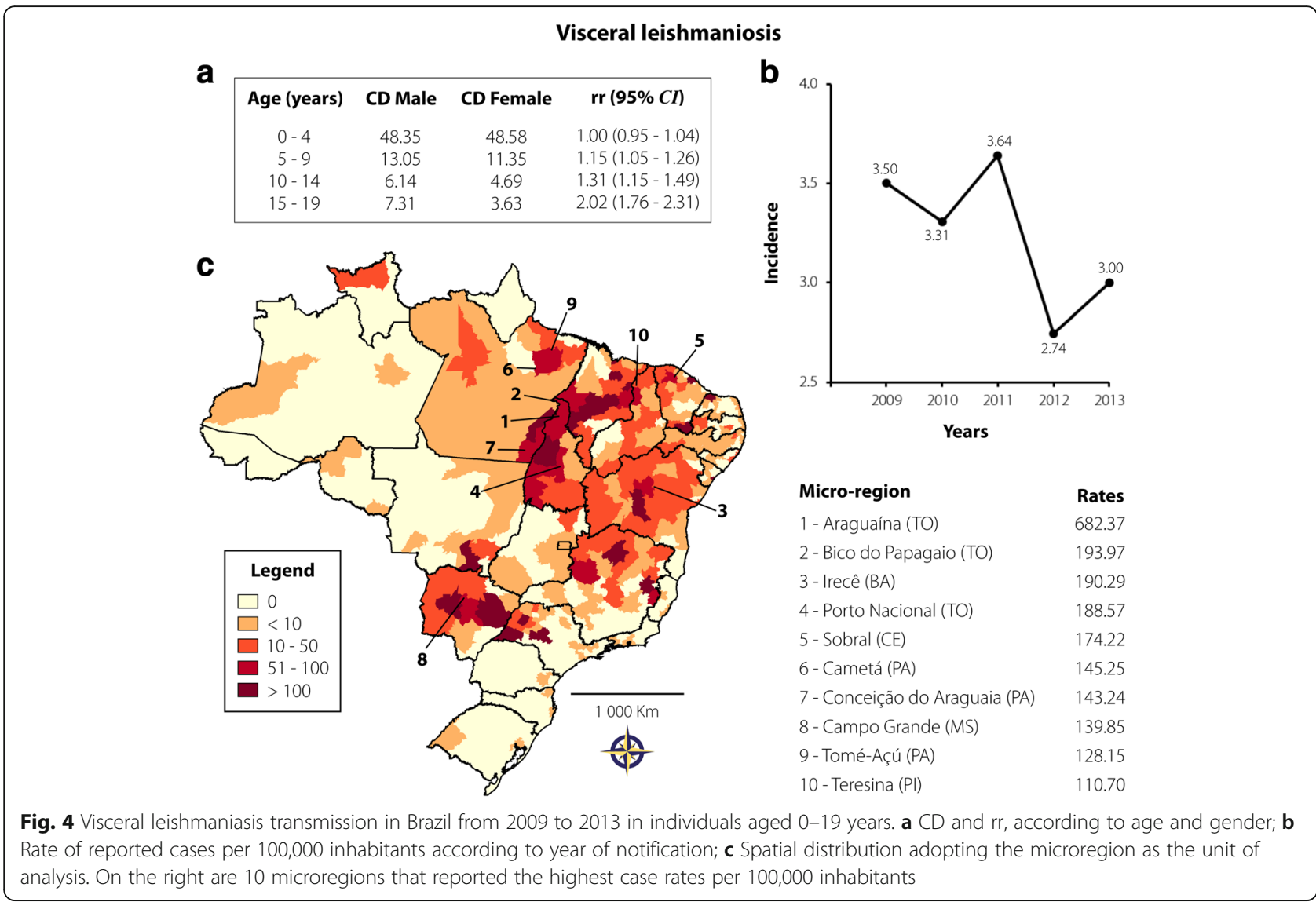

Leishmaniasis is estimated to cause 1.6 million new cases worldwide each year, of which an estimated 1.1 million are cutaneous and 500,000 are visceral. However, of the 1.6 million estimated cases, 1 million remain unreported [20]. Since the late 1990s, Brazil has experienced an increase in the number of leishmaniasis cases, owing to the introduction of the parasite into suburban areas of large cities, resulting from the large-scale migration of people [20]. Indeed, a significant spatial distribution of CL in all Brazilian regions was identified in our study, constituting a widespread problem for public health. The vast majority of the reported cases occurred in the North region, more precisely in certain microregions of the Acre, Amazonas, Roraima, and Amapá states, with more than 11,946 cases per 100,000 inhabitants aged up to 19 years. Furthermore, clusters of microregions were identified with rates of over 750 reported cases per 100,000 in the states of Mato Grosso (Paranatinga and Tesouro microregions) and Ceará (Meruoca microregion). One particular microregion of southern Bahia caught the authors' attention: Valença, characterized by approximately 5000 reported cases per 100,000 inhabitants aged up to 19 years. One village located in this microregion, Corte de Pedra, is recognized as one of the most important areas of Leishmania braziliensis transmission in Brazil. In general, CL in this region may be considered an occupational disease, since most of the infected individuals are members of the agricultural workforce, which means that healthy individuals are put in close contact with the wild cycle of the parasite, creating a high risk of exposure to infected phlebotomine bites. The village has experienced a sharp increase in the number of CL cases since 1983 [29, 30], leading to an outbreak in 1986 [31]. The last epidemiological study revealed an annual incidence of 8.1 cases per 1000 inhabitants and a prevalence of 14.9\% [32].

Similarly, VL cases were identified in all Brazilian states, with greater concentrations in microregions located in the centre of the country. Araguaína (Tocantins state) had the highest rate: approximately 682 cases per 100,000 inhabitants aged up to 19 years. Our rate of reported cases is higher than the 578.39 cases (per 100,000) estimated in a cross-sectional study of children below 15 years of age, which was carried out in the municipality of Araguaína in 2007 [33]. The higher rate obtained in this study indicates an increase in the number of cases since the cross-sectional study was conducted. Cases of VL were also reported with a high burden (> 100 cases/100000 inhabitants aged up to 19 years) in other microregions, mainly in the North 


\section{Malaria}
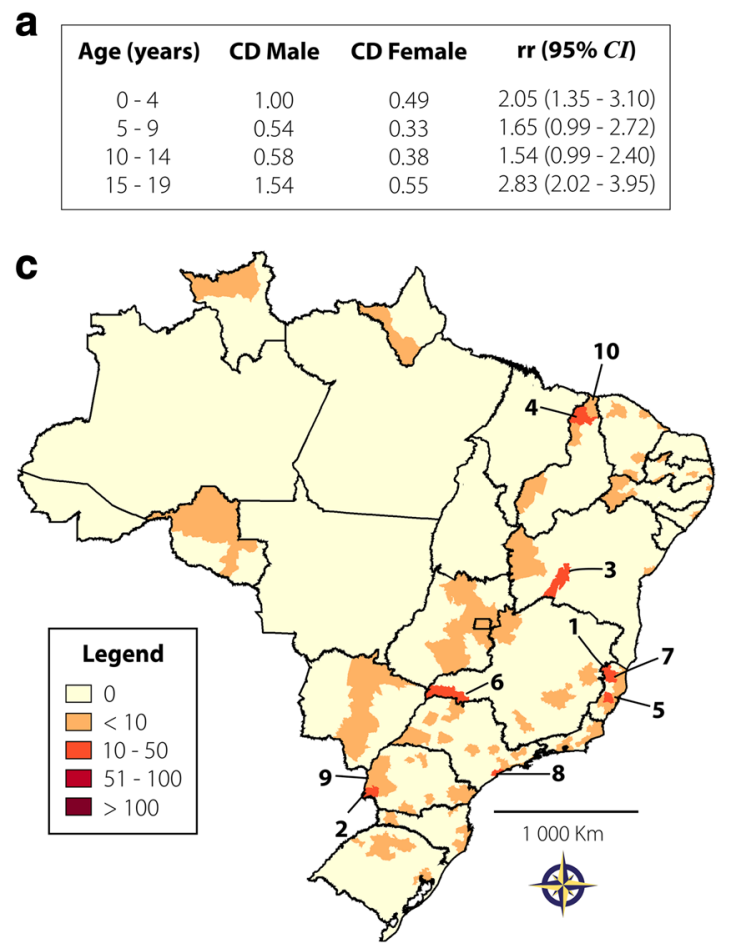

b

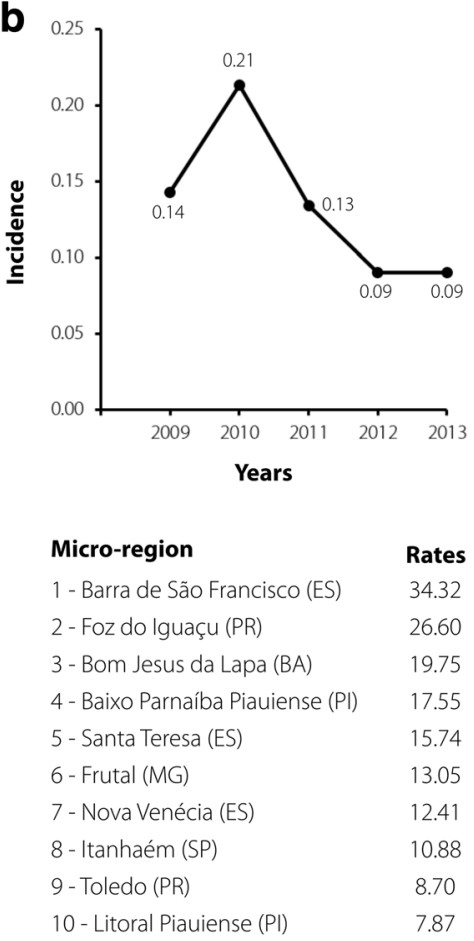

Fig. 5 Malaria transmission in Brazil from 2009 to 2013 in individuals aged 0-19 years. a CD and rr, according to age and gender; b Rate of reported cases per 100,000 inhabitants according to year of notification; c Spatial distribution adopting the microregion as the unit of analysis. On the right are 10 microregions that reported the highest case rates per 100,000 inhabitants

(Tocantins and Pará states); Northeast (Bahia, Ceará, and Piauí states); and Central-West regions (Mato Grosso do Sul state). Visceral leishmaniasis is potentially fatal if not treated promptly, mainly when associated with other risk factors, such as increased age, malnutrition, and immunosuppression. With respect to immunosuppression, it was observed that approximately $7 \%$ of VL cases were co-infected with HIV. According to Monge-Maillo and López-Vélez [34], VL and HIV coinfection has significant clinical, diagnostic, and epidemiological implications, favouring the reactivation of latent leishmaniasis, inducing a more severe manifestation of the disease, increasing the risk of relapse after treatment, and leading to a poorer therapeutic response.

Although commonly reported, CL showed low death rates compared with VL. If not treated in time, VL has a high mortality rate, with estimates varying between 80 and $100 \%$. Even with treatment, fatality rates exceed $10 \%$ [35]. In Bangladesh, a study reported case-fatality rates of $6 \%$ and $8 \%$ among males and females below 15 years of age, respectively [35]. A high mortality rate was reported in Sergipe in Brazil from 1980 to 2013. During this period, $11.8 \%$ of deaths were attributed to VL [36]. In this study, however, a lower rate of death in individuals aged up to 19 years was found (3.72\%).
Approximately 207 million people may have schistosomiasis worldwide, with an additional 779 million at risk of infection [37]. In Brazil, 2.5 million individuals are considered infected and 25 million are at risk of infection [38]. People become infected during contact with freshwater bodies infested with cercariae released by specific intermediate host snails when conducting recreational, domestic, and occupational activities. With regards to geographical distribution, the situation is different to that found for both cutaneous and visceral leishmaniasis. Even though a large proportion of the Brazilian states reported new cases of schistosomiasis, we observed a big concentration in Minas Gerais, Espírito Santo, and the coastal area of some Northeast states. The Téofilo Otoni microregion (Minas Gerais state) conferred the highest number of reported cases per 100,000 inhabitants aged up to 19 years. Indeed, a study carried out in Malacacheta, a municipality located in Téofilo Otoni, highlighted the high prevalence of infection by $S$. mansoni in schoolchildren, mainly in boys aged $\geq 11$ years living in rural areas [39]. Similarly, a significant proportion of reported cases was found among boys aged 10-19 years. Exposure to leisure activities associated with river water may be related to the greater occurrence in this group. In this study, schistosomiasis 


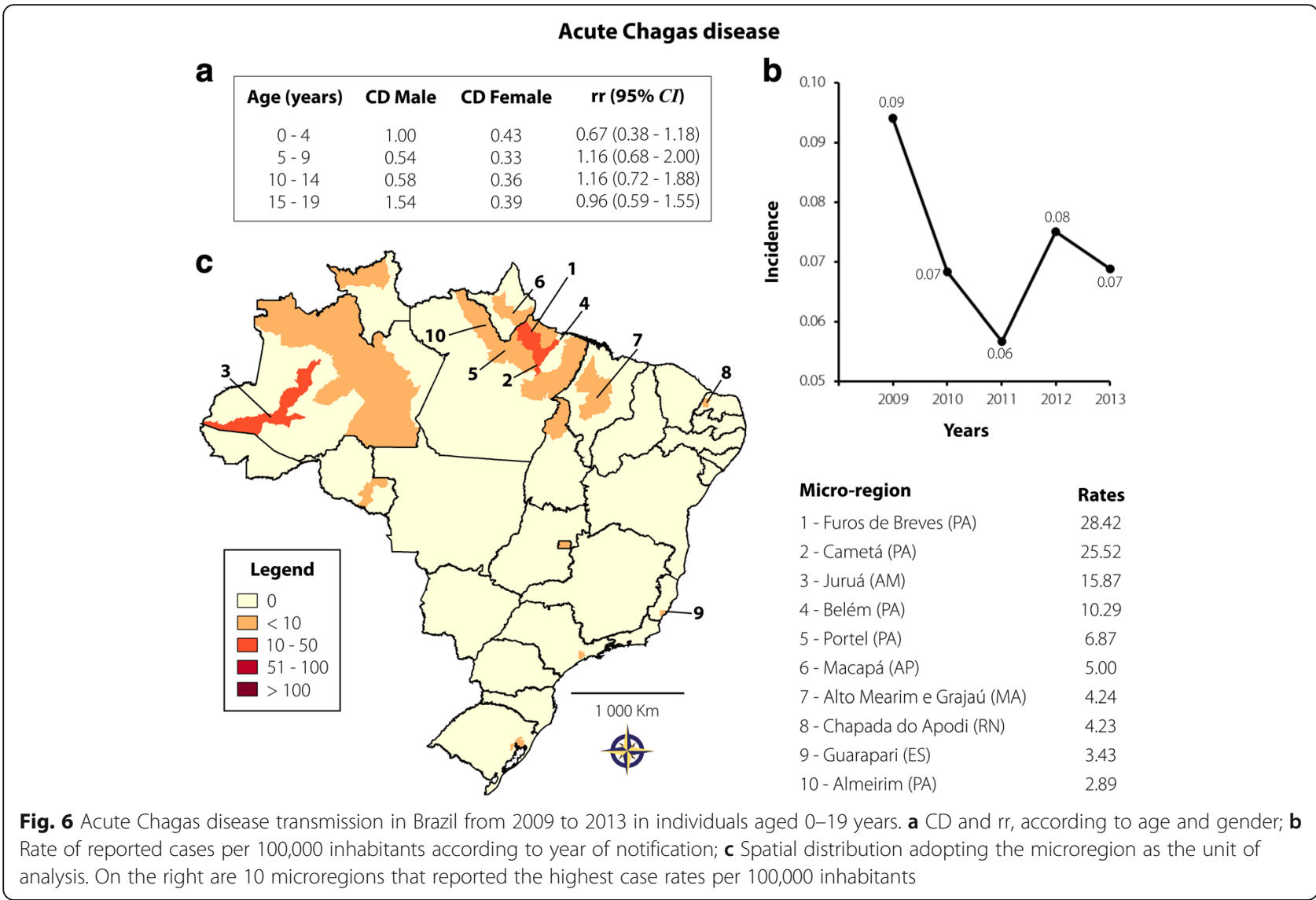

presented low mortality rates. A study conducted in Brazil in 2007 revealed a $62.9 \%$ reduction in the mortality rate of schistosomiasis [40].

The past decade has seen the world make considerable progress in reducing malaria cases and deaths. However, most endemic areas are still far from achieving coverage with antimalaria programs. Globally, an estimated 198 million people have become infected with Plasmodium spp. and 584,000 people have died of malaria, with the heaviest burden in African countries, where children aged below 5 years account for $78 \%$ of all deaths [41]. Brazil contributed with a reduction in incidence of 76.8\% between 2000 and 2014. Nevertheless, transmission remains dominant in the Amazon region, accounting for almost all reported cases in Brazil [42]. In contrast, our study did not show reported cases in the Amazonas, Acre, Tocantins, and Pará states, suggesting either successful prevention campaigns, underreported cases, or both. Although malaria prevalence has gradually been declining in Brazil [43, 44], we believe that the number of underreported cases in the North region is high, as some studies have described cases in children $[45,46]$ in this area. On the other hand, the spatial distribution of malaria has been found to be heterogeneous in other Brazilian regions. Cases were reported with either lesser or greater intensity in microregions of the Northeast, Southeast, and South regions. Indeed, microregions with more than 15 cases per 100,000 inhabitants aged up to 19 years are spatially far from one another, suggesting that control campaigns against Plasmodium spp. should be mandatory nationwide.

Between 2001 and 2006, 2476 cases of acute Chagas disease $(64.7 \%$ vectorial, $0.7 \%$ transfusional, $0.3 \%$ transplacental, and $34.3 \%$ of unknown transmission route) were reported in Brazil [47]. However, as previously mentioned, the Southern Cone Initiative has changed the epidemiological profile of the disease, as the country has received international certification for the interruption of vectorial transmission by T. infestans in 2006. In fact, a study carried out in Pernambuco state showed a significant decrease in new cases starting in 2006 [25]. Because of the decrease in vectorial transmission in Brazil, attention should be directed to the new cases that occur through contaminated food and beverages in endemic areas [48]. In this study, a high burden of acute Chagas disease in the states of the Amazon Basin, mainly Amazonas and Pará, was found. Oral transmission of this disease in the Amazon region has been reported since the 1960s and our data are in agreement with previous studies $[49,50]$. Acute Chagas disease, the 
NTD with the lowest number of reported cases, was shown to be responsible for $1.72 \%$ of deaths in inhabitants aged up to 19 years. The high death rate for Chagas disease is a peculiar characteristic of endemic countries in Latin America. However, deaths attributed to Chagas disease are more common in individuals aged over 40 years, who had probably acquired the infection earlier in their lives $[36,51]$. Acute Chagas diasease was also the most common cause of mortality in the general population in a study that assessed reported cases from 2000 to 2011, revealing a significant public health problem in Brazil [52].

\section{Conclusions}

The number of cases and the lethality rate described show that the four NTDs examined in this study still represent a serious public health problem in Brazil. This points to the need to encourage new research and the reformulation of social, economic, and public health policies aimed at ensuring better health and living conditions for all individuals, especially those among the populations considered vulnerable, as is the case of the young. The analysis of the geographical distribution of these NTDs enables the identification of priority areas for the development and intensification of control and elimination initiatives.

\section{Additional files}

Additional file 1: Multilingual abstracts in the five official working languages of the United Nations. (PDF $667 \mathrm{~kb}$ )

Additional file 2: Neglected diseases: the strategies of the Brazilian Ministry of Health. (PDF $100 \mathrm{~kb}$ )

\section{Abbreviations}

Cl: Confidence interval; CL: Cutaneous leishmaniasis; IBGE: Brazilian Institute of Geography and Statistics; NTD: Neglected tropical disease; SINAN: Health Notification Aggravation Information System; VL: Visceral leishmaniasis; WHO: World Health Organization

\section{Acknowledgements}

We thank Dr. Wanderley for reviewing the information on schistosomiasis.

\section{Funding}

Not applicable.

\section{Availability of data and materials}

All data presented in the study can be accessed in the SINAN and IBGE databases (available at http://datasus.saude.gov.br and http:// www.ibge.gov.br, respectively).

\section{Authors' contributions}

All authors contributed equally to the design of the study. FLNS was responsible for the geoprocessing analysis. EB and FLNS were responsible for most of the writing. SR prepared the first version of the paper. MALS revised and finalized the paper. All authors read and approved the final paper.

\section{Ethics approval and consent to participate}

This investigation was performed according to public domain data without the possibility of identifying subjects, thereby dispensing the need for approval by an institutional review board for human research.
Consent for publication

Not applicable.

\section{Competing interests}

The authors declare that they have no competing interests.

\section{Author details}

${ }^{1}$ National Reference Service for Filariasis, Aggeu Magalhães Institute (Fiocruz-PE), Recife, Pernambuco, Brazil. '2Faculty of Medical Sciences, National University of Rosario, Rosario, Santa Fe, Argentina. ${ }^{3}$ Laboratory of Communicable Diseases, Parasitology Department, Aggeu Magalhães Institute (Fiocruz-PE), Recife, Pernambuco, Brazil. ${ }^{4}$ Laboratory of Pathology and Bio-Intervention, Gonçalo Moniz Institute (Fiocruz-BA), Salvador, Bahia, Brazil.

Received: 6 April 2017 Accepted: 13 October 2017

Published online: 03 November 2017

\section{References}

1. World Health Organization. Working to overcome the global impact of neglected tropical diseases - summary. Wkly Epidemiol Rec. 2011;86(13):113-20.

2. Hotez PJ. Neglected infections of poverty in the United States of America. PLoS Negl Trop Dis. 2008;2(6):e256. 10.1371/journal.pntd.0000256.

3. Departamento de Ciência e Tecnologia, Secretaria de Ciência, Tecnologia e Insumos Estratégicos, Ministério da Saúde. Doenças negligenciadas: estratégias do Ministério da Saúde. Rev Saude Publica. 2010;44(1):200-2. 10. 1590/S0034-89102010000100023. (in Portuguese)

4. Brasil. Lista Nacional de Notificação Compulsória de doenças, agravos e eventos de saúde pública nos serviços de saúde públicos e privados em todo o território nacional. Ministério da Saúde. 2014. http://bvsms.saude. gov.br/bvs/saudelegis/gm/2014/prt1271_06_06_2014.html. Accessed 12 Mar 2017. (in Portuguese).

5. Brasil. Doenças negligenciadas: estratégias do Ministério da Saúde. Rev Saúde Pública. 2010;44(1):200-2.

6. Pelletier DL. The potentiating effects of malnutrition on child mortality: epidemiologic evidence and policy implications. Nutr Rev. 1994;52:409-15.

7. Jones KDJ, Berkley JA. Severe acute malnutrition and infection. Paediatr Int Child Health. 2014;34(Suppl 1):1-29. 10.1179/2046904714Z.000000000218.

8. Lyra MR, Pimentel MI, Madeira Mde F, Antonio Lde F, Lyra JP, Fagundes A, et al. First report of cutaneous leishmaniasis caused by Leishmania (Leishmania) infantum chagasi in an urban area of Rio de Janeiro, Brazil. Rev Inst Med Trop Sao Paulo. 2015;57(5):451-4. 10.1590/S003646652015000500016

9. de Araújo VE, Pinheiro LC, Almeida MC, de Menezes FC, Morais MH, Reis IA, et al. Relative risk of visceral leishmaniasis in Brazil: a spatial analysis in urban area. PLoS Negl Trop Dis. 2013;7(11):e2540. 10.1371/journal.pntd.0002540.

10. Druzian AF, Souza AS, Campos DN, Croda J, Higa MG, Dorval ME, et al. Risk factors for death from visceral leishmaniasis in an urban area of Brazil. PLoS Negl Trop Dis. 2015;9(8):e0003982. 10.1371/journal.pntd.0003982.

11. Oliveira CD, Morais MH, Machado-Coelho GL. Visceral leishmaniasis in large Brazilian cities: challenges for control. Cad Saude Publica. 2008;24(12):2953-8.

12. Souza W. Doenças negligenciadas. Academia Brasileira de Ciências. 2010. https://www.abc.org.br/IMG/pdf/doc-199.pdf. Accessed 25 Mar 2017.

13. Müller I, Hailu A, Choi BS, Abebe T, Fuentes JM, Munder M, et al. Agerelated alteration of arginase activity impacts on severity of leishmaniasis. PLoS Negl Trop Dis. 2008;2(5):e235. 10.1371/journal.pntd.0000235.

14. Queiroz MJ, Alves JG, Correia JB. Leishmaniose visceral: características clínicoepidemiológicas em crianças de área endêmica. J Pediatr. 2004;80(2):141-6.

15. World Health Organization. World malaria report 2016. Geneva:WHO; 2016. [Internet] Available from: http://apps.who.int/iris/bitstream/10665/252038/1/ 9789241511711-eng.pdf. Accessed 05 may 2017.

16. Fernandes FB, Lopes RGC, Mendes Filho SPM. Severe malaria in pregnant women. Rev Bras Ginecol Obstet. 2010;32(12):579-83.

17. Pan American Health Organization/World Health Organization. Schistosomiasis regional meeting. Defining a road map toward verification of elimination of schistosomiasis transmission in Latin America and the Caribbean by 2020. Isla Verde Carolina; Tuesday, October 21 to Wednesday, October 22, 2014. p. 63.

18. Zhang CY, Yuan WG, He P, Lei JH, Wang CX. Liver fibrosis and hepatic stellate cells: etiology, pathological hallmarks and therapeutic targets. World J Gastroenterol. 2016;22(48):10512-22. 10.3748/wjg.v22.i48.10512. 
19. Stothard JR, Campbell SJ, Osei-Atweneboana MY, Durant T, Stanton MC, Biritwum NK, et al. Towards interruption of schistosomiasis transmission in sub-Saharan Africa: developing an appropriate environmental surveillance framework to guide and to support "end game" interventions. Infect Dis Poverty. 2017;6(1):10. 10.1186/s40249-016-0215-9.

20. World Health Organization. Working to overcome the global impact of neglected tropical diseases - first WHO report on neglected tropical diseases. Geneva:WHO; 2010. [Internet] Available from: http://apps.who.int/iris/bitstream/ 10665/44440/1/9789241564090_eng.pdf. Accessed 22 Feb 20175.

21. World Health Organization. Chagas disease in Latin America: an epidemiological update based on 2010 estimates. Wkly Epidemiol Rec 2015;90(6):33-43.

22. Global Burden of Disease Study 2013 Collaborators. Global, regional, and national incidence, prevalence, and years lived with disability for 301 acute and chronic diseases and injuries in 188 countries, 1990-2013: a systematic analysis for the global burden of disease study 2013. Lancet. 2015;386(9995): 743-800. 10.1016/S0140-6736(15)60692-4.

23. Hotez PJ, Dumonteil E, Woc-Colburn L, Serpa JA, Bezek S, Edwards MS, et al. Chagas disease: "the new HIV/AIDS of the Americas". PLoS Negl Trop Dis. 2012;6(5):e1498. 10.1371/journal.pntd.0001498.

24. Dias JCP. Southern cone initiative for the elimination of domestic populations of Triatoma infestans and the interruption of transfusional Chagas disease. Historical aspects, present situation, and perspectives. Mem Inst Oswaldo Cruz. 2007;102(Suppl 1):11-8.

25. Santos FL, Lorena VM, Souza WW, Gomes YM. Spatiotemporal analysis of reported cases of acute Chagas disease in the state of Pernambuco, Brazil, from 2002 to 2013. Rev Soc Bras Med Trop. 2015;48(2):181-7. 10.1590/0037-8682-0312-2014.

26. Ostermayer AL, Passos AD, Silveira AC, Ferreira AW, Macedo V, Prata AR. O inquérito nacional de soroprevalência de avaliação do controle da doença de Chagas no Brasil (2001-2008). Rev Soc Bras Med Trop. 2011;44(Suppl 2):108-21.

27. Barbosa CS, Santos RS, Gomes ES, Araújo K, Albuquerque J, Melo F, et al. Epidemiologia da esquistossomose no litoral de Pernambuco. Rev Patol Trop. 2015;43(4):436-45. 10.5216/rpt.v43i4.33607.

28. Cavalcante IJ, Vale MR. Epidemiological aspects of visceral leishmaniasis (kala-azar) in Ceará in the period 2007 to 2011. Rev Bras Epidemiol. 2014; 17(4):911-24.

29. Costa JM, Tada MS, Netto EM, Vale KC, Lago EL, Marsden PD. Procedência de pacientes portadores de leishmaniose tegumentar americana nas áreas endêmicas de Três Braços e Corte de Pedra - Estado da Bahia - Brasil. Rev Soc Bras Med Trop. 1988;21(3):145-9. 10.1590/50037-86821988000300009 (in Portuguese)

30. Costa JM, Vale KC, França F, Costa MA, Silva JO, Lago EL, et al. A leishmaniose tegumentar americana em uma região endêmica como fator de mobilização comunitária. Rev Soc Bras Med Trop. 1994;27(4):255-7. 10. 1590/S0037-86821994000400010. (in Portuguese)

31. Costa JM, Tada MS, Lago EL, França F, Vale KC, Osaki N, et al. Surto epidêmico de leishmaniose tegumentar americana na região de Corte de Pedra (BA). Rev Soc Bras Med Trop. 1986;19(Suppl):161. (in Portuguese)

32. Jones $T C$, Johnson WD, Barretto $A C$, Lago E, Badaro R, Cerf B, et al. Epidemiology of American cutaneous leishmaniasis due to Leishmania braziliensis braziliensis. J Infect Dis. 1987;156(1):73-83.

33. Oliveira IB, Batista HL, Peluzio JM, Pfrimer IA, Rodrigues FM, Carmo Filho JR. Epidemiological and environmental aspects of visceral leishmaniasis in children under 15 years of age between 2007 and 2012 in the City of Araguaína, state of Tocantins, Brazil. Rev Soc Bras Med Trop. 2014;47(4):476-82.

34. Monge-Maillo B, López-Vélez R. Treatment options for visceral leishmaniasis and HIV coinfection. AIDS Rev. 2016;18(1):32-43.

35. Ahluwalia IB, Bern C, Costa C, Akter T, Chowdhury R, Ali M, et al. Visceral leishmaniasis: consequences of a neglected disease in a Bangladeshi community. Am J Trop Med Hyg. 2003;69(6):624-8.

36. Costa de Albuquerque MA, Dias DM, Vieira LT, Lima CA, da Silva AM. Mortality trends for neglected tropical diseases in the state of Sergipe, Brazil, 1980-2013. Infect Dis Poverty. 2017;6(1):20. 10.1186/s40249-016-0232-8.

37. Steinmann P, Keiser J, Bos R, Tanner M, Utzinger J. Schistosomiasis and water resources development: systematic review, meta-analysis, and estimates of people at risk. Lancet Infect Dis. 2006;6(7):411-25.

38. Katz N, Peixoto SV. Análise crítica da estimativa do número de portadores de esquistossomose mansoni no Brasil. Rev Soc Bras Med Trop. 2000;33(3): 303-8. 10.1590/S0037-86822000000300009. (in Portuguese).

39. Cabello RK, Beck LC, Massara CL, Murta FL, Guimarães RJ, Pieri OS, et al. Schistosoma mansoni infection and related knowledge among schoolchildren in an endemic area of Minas Gerais, Brazil, prior to educational actions. Acta Trop. 2016;164:208-15. 10.1016/j.actatropica.2016.09.015.

40. Ferreira ILM, Silva TPT. Mortality by schistosomiasis in Brazil: 1980-2003. Rev Patol Trop. 2001;36(1):67-74.

41. World Health Organization. World malaria report 2014. Geneva: WHO; 2014. [Internet] Available from: http://www.who.int/malaria/publications/world_ malaria_report_2014/en/. Accessed 20 Feb 2017.

42. Ferreira MU, Castro MC. Challenges for malaria elimination in Brazil. Malar J. 2016;15(1):284. 10.1186/s12936-016-1335-1.

43. Tauil PL. Evaluation of a new strategy in the control of malaria in tha Brazilian Amazonia. Rev Inst Med Trop S Paulo. 2003:45(6):1. 10.1590/S003646652003000600011

44. Silva AR, Cavaleiro NN, Guimarães MC, Gonçalves EG. Evolução da malária no estado do Maranhão: série histótica de 2009 a 2013. Rev Patol Trop. 2016:45(1):33-41. 10.5216/rpt.v45i1.39977. (in Portuguese)

45. Noronha E, Alecrim MG, Romero GA, Macedo V. Estudo clínico da malária falciparum em crianças em Manaus, AM, Brasil. Rev Soc Bras Med Trop. 2000;33(2):185-90. 10.1590/S0037-86822000000200005. (in Portuguese)

46. Silva NS. Epidemiologia da malária: incidência, distribuição espacial e fatores de risco em uma coorte rural amazônica. University of São Paulo. 2011. http://www.teses.usp.br/teses/disponiveis/42/42135/tde-04082011-102334/ en.php. Accessed 15 Jan 2017. (in Portuguese).

47. Lannes-Vieira J, Soeiro Mde NC, Corrêa-Oliveira R, de Araújo-Jorge TC. Chagas disease centennial anniversary celebration: historical overview and prospective proposals aiming to maintain vector control and improve patient prognosis - a permanent challenge. Mem Inst Oswaldo Cruz. 2009; 104(Suppl 1):5-7. 10.1590/S0074-02762009000900003.

48. Pereira KS, Schmidt FL, Guaraldo AM, Franco RM, Dias VL, Passos LA. Chagas' disease as a foodborne illness. J Food Prot. 2009;72(2):441-6.

49. Beltrão Hde BM, Cerroni Mde P, Freitas DR, Pinto AY, Valente Vda C, Valente SA, et al. Investigation of two outbreaks of suspected oral transmission of acute Chagas disease in the Amazon region, Para state, Brazil, in 2007. Trop Dr. 2009:39(4):231-2. 10.1258/td.2009.090035.

50. Nóbrega AA, Garcia MH, Tatto E, Obara MT, Costa E, Sobel J, et al. Oral transmission of Chagas disease by consumption of açaí palm fruit, Brazil. Emerg Infect Dis. 2009;15(4):653-5. 10.3201/eid1504.081450.

51. Alves RM, Thomaz RP, Almeida EA, Wanderley JS, Guariento ME. Chagas' disease and ageing: the coexistence of other chronic diseases with Chagas' disease in elderly patients. Rev Soc Bras Med Trop. 2009:42(6):622-8.

52. Martins-Melo FR, Ramos AN, Alencar CH, Heukelbach J. Mortality from neglected tropical diseases in Brazil, 2000-2011. Bull World Health Organ. 2016;94(2):103-10. 10.2471/BLT.15.152363.

\section{Submit your next manuscript to BioMed Central and we will help you at every step:}

- We accept pre-submission inquiries

- Our selector tool helps you to find the most relevant journal

- We provide round the clock customer support

- Convenient online submission

- Thorough peer review

- Inclusion in PubMed and all major indexing services

- Maximum visibility for your research

Submit your manuscript at www.biomedcentral.com/submit
Biomed Central 